\title{
Concurrent high-intensity aerobic and resistance exercise modulates systemic release of alarmins (HMGB1, S100A8/A9, HSP70) and inflammatory biomarkers in healthy young men: a pilot study
}

Jorming Goh ${ }^{1,2^{*}}$, Peter Hofmann ${ }^{3}$, Ning Hong Aw ${ }^{4,5}$, Poh Ling Tan ${ }^{1}$, Gerhard Tschakert ${ }^{3}$, Alexander Mueller ${ }^{3}$, Siew Cheng Wong ${ }^{6}$, Frankie $\operatorname{Tan}^{7}$ and Linda Seo Hwee Gan ${ }^{1}$

\begin{abstract}
Background: Intense exercise is a systemic stressor associated with the release of "danger" molecules - alarmins, by damaged or dying cells into systemic circulation to evoke a sterile inflammatory response. Compared with research in clinical diseases, physiological responses of alarmins to exercise and training are not well studied. Shortterm responses to exercise and training using a panel of alarmins - HMGB1, S100A8/A9, HSP70 and sRAGE may reveal unique aspects of stress responses to strenuous exercise, with important ramifications when prescribing exercise to generally healthy adults.

Methods: A 3-week, high-intensity training program was performed by healthy young men $(N=7)$. Concurrent aerobic and resistance exercises were performed on 3 consecutive days each week. Blood and saliva were collected before (Pre), immediately after (Post), and $30 \mathrm{~min}(30 \mathrm{~min})$ after exercise each week, and $24 \mathrm{~h}$ after the final exercise session in week $3(24 \mathrm{~h})$.

Results: Plasma HMGB1, S100A8/A9 and HSP70 increased from Pre to Post $(P<0.05)$, although at different timepoints during the study, and displayed different kinetics from IL-10, IL-8 and IFN- $\gamma$, suggesting unique mechanisms involved in modulating their release and clearance. $\mathrm{CD} 14^{+} \mathrm{CD} 16^{-}$monocytes increased from Pre to Post across 3 weeks; $\mathrm{CD} 14^{+} \mathrm{CD}_{16}{ }^{+}$monocytes increased from Pre to Post in week 2 and $3(P<0.05)$. $\Delta \mathrm{HMGB1}$ and $\triangle H S P 70$ correlated positively with $\triangle M C P-1$ during 3 weeks of training. As well, $\triangle H M G B 1$ correlated positively with $\mathrm{CD} 14^{+} \mathrm{CD} 16^{-}$monocytes, suggesting higher alarmin release after strenuous exercise may involve increase in circulating monocytes.
\end{abstract}

Conclusions: Perturbations in systemic alarmins are novel biological signatures for assessing the inflammatory milieu of healthy adults during high-intensity exercise.

Keywords: Exercise, Alarmins, HMGB1, S100A8/A9, HSP70, sRAGE

\footnotetext{
* Correspondence: jorming@nus.edu.sg

'Defence Medical \& Environmental Research Institute (DMERI), DSO National Laboratories, Singapore, Singapore

${ }^{2}$ Present Address: Centre for Healthy Longevity, National University Health System (NUHS) and Department of Physiology, Yong Loo Lin School of

Medicine, National University of Singapore, Singapore, Singapore

Full list of author information is available at the end of the article
}

(C) The Author(s). 2020 Open Access This article is licensed under a Creative Commons Attribution 4.0 International License, which permits use, sharing, adaptation, distribution and reproduction in any medium or format, as long as you give appropriate credit to the original author(s) and the source, provide a link to the Creative Commons licence, and indicate if changes were made. The images or other third party material in this article are included in the article's Creative Commons licence, unless indicated otherwise in a credit line to the material. If material is not included in the article's Creative Commons licence and your intended use is not permitted by statutory regulation or exceeds the permitted use, you will need to obtain permission directly from the copyright holder. To view a copy of this licence, visit http://creativecommons.org/licenses/by/4.0/. 


\section{Background}

Intense acute exercise has been compared to a state of mild trauma, with the systemic inflammatory response after a bout of heavy endurance exercise mimicking that of clinical sepsis [1]. During intense exercise, multiple organ systems experience increased physiological stress, including cyclic bouts of ischemia-reperfusion and hypoxia in contracting skeletal muscles, increased oxidative stress, changes in body temperature and metabolic substrate flux as well as shunting of blood flow from visceral organs to contracting skeletal muscles. Taking reference from Matzinger's "danger" model [2], such disturbances in systemic homeostasis can be sensed by the immune system and result in the activation of the sterile inflammatory response. The immune system plays a role in modulating physiological adaptation to exercise stimuli - in essence, its response entails the recruitment of specific leukocytes for the mitigation of cellular damage, especially in skeletal muscle. It is plausible that alarmins, as "danger" signals, may play a role in the adaptation to exercise training.

Alarmins are endogenous molecules that activate the immune system when encountering "danger" to the host, such as in the case of infection or cellular stress/damage [2-4]. During homeostasis, alarmins are sequestered within the cytosol or nucleus and perform regulatory functions [5]. Stressed or damaged cells can quickly release alarmins into systemic circulation, where they bind pattern recognition receptors (PRRs) on antigen presenting cells to activate the immune system [6]. Since the first study on alarmins was published, the list of putative alarmins has grown and currently include high mobility group box protein-1 (HMGB1), high-mobility group nucleosome-binding protein 1 (HMGN1), S100 proteins, heat shock proteins (HSPs), cathelicidin, eosinophil-derived neurotoxin (EDN), defensins, granulysin and mitochondrial DNA, mitochondrial peptides and ATP [3].

The concept of alarmins as "danger" signals has been studied in various clinical diseases, such as polytrauma [7], heat stroke [8, 9], cardiovascular disease [10] and cancer [11]. Although the phenomenon of exercise-induced inflammatory cytokine responses is well-established [11], the responses of alarmins to exercise are poorly understood and represent an exciting research vista. In brief, investigators have mostly described the effects of acute exercise (one bout of exercise) on individual alarmins, with only one research group [12] having studied them as a part of a panel of biomarkers. Furthermore, alarmins as a panel of biomarkers have never been studied within the context of exercise training. Nevertheless, separate findings from these studies show that acute exercise increases circulating alarmins, such as HMGB1, and supports our working hypothesis that strenuous/exhaustive exercise is a "danger" or stressor to the physiological system [13].
Systemic HMGB1 increased after strenuous aerobic exercise, including exhaustive treadmill running [14], a half- or full-marathon race [12] and a 5-min step test in a hypoxic chamber [15]. Likewise, serum HSP70 increased after a single bout of treadmill running in an ambient environment $\left(20^{\circ} \mathrm{C}\right)$ at an intensity of $70 \% \mathrm{VO}_{2}$ peak for $60 \mathrm{~min}$ [16] and also after $2 \mathrm{~h}$ of semi-recumbent cycling at $\sim 60 \% \mathrm{VO}_{2} \max$ [17]. Finally, systemic S100A8/A9 increased after highintensity interval or continuous cycling [18], $3 \mathrm{~h}$ of dynamic knee extension [19], as well as treadmill running $\left(75 \% \mathrm{VO}_{2}\right.$ $\max , 30 \mathrm{~min}$ ) [20], but not to one-legged calf-raise exercise (10 sets $\times 40$ repetitions) [21]. While most of the studies confirm the systemic elevation of alarmins after acute exercise, it is unclear how an acute bout of exercise affects the responses of different alarmins, as this has not been studied. Furthermore, the impact on systemic release of alarmins after a period of exercise training is unclear since no studies have investigated training effects on alarmins.

The "repeated bout effect" is a phenomenon describing physiological adaptations to unaccustomed high-intensity exercise, wherein the initial increase in inflammatory cytokines and proteins associated with muscle damage and soreness are attenuated after repeated bouts of exercise [22]. The release of cytokines and chemokines from tissue macrophages may mediate this beneficial adaptation [22] Furthermore, exercise-induced release of prototypical alarmins such as HMGB1, HSP70 and S100A8/A9 represent "danger" signals that can also orchestrate the migration of monocytes and macrophages to skeletal muscle for tissue repair [23-25] or to prime them for activation [26]. For instance, the resultant protein complex formed from the binding of HMGB1 and receptor for advanced glycation end products (RAGE) could activate downstream inflammatory responses, such as the chemotaxis and adhesion of monocytes at sites of injury [27], modulating the production of inflammatory cytokines such as TNF- $\alpha$ [28] and activation of other immune cells, such as natural killer cells [28].

Applying concepts from the "danger" model [2, 29], we speculate that the physiological and mechanical stress imposed by unaccustomed, strenuous exercise across repeated, multiple sessions, can activate danger signaling and result in increased alarmins in blood circulation. This study is novel as it is the first to investigate the cumulative effects of multiple days of intense exercise training on different alarmins that are normally sequestered in various cellular compartments (nucleus and cytosol) during homeostasis. The effects of this exercise program are also investigated for multiple aspects of immune function, including cytokines, chemokines and monocyte subsets. Understanding the responses of alarmins to intense exercise training, a form of physiological stress, can reveal novel mechanistic links between immune activation and subsequent systemic responses 
(e.g. cytokine release, increased body temperature, muscle damage).

\section{Materials and methods Subjects}

Healthy men $(N=7$; means \pm SD: $24.9 \pm 2$ yrs $)$ without cardiovascular, metabolic or respiratory disease were recruited from the general public and completed all exercise trials. All subjects were recreationally active and participated in sports/exercise for a minimum of $30 \mathrm{~min}$, at least three times a week. None of the subjects were taking nutritional supplementation for weight gain or weight loss, nor taking supplemental vitamins or minerals.

\section{Physical activity monitoring}

All subjects recorded their habitual physical activity on the short version of the international physical activity questionnaire (I-PAQ). Further, subjects were asked to refrain from any form of recreational and competitive sports or exercise training during the entirety of this study, except for the exercises prescribed in the study. Weekly expended metabolic equivalents (METS) were calculated based on formulas designed by Craig et al. [30], and included energy expenditure for walking, moderate physical activity and vigorous physical activity.

\section{Diet monitoring}

Subjects were asked to adhere to a self-selected weekly diet, which was kept the same for 3 weeks. Each subject recorded his daily food intake in a food diary throughout the entire study. Finally, subjects fasted overnight (allowed plain water) prior to each trial visit. The energy and nutrient composition of the diets were assessed using an interactive nutrient analysis tool designed by the Singapore Health Promotion Board (http://focos.hpb.gov.sg/eservices/ENCF/).

\section{Baseline cardiorespiratory and strength tests}

A $\mathrm{VO}_{2}$ peak test and 10-repetition maximum (10-RM) test were administered at baseline, a week prior to the first exercise training session, in order to determine cardiorespiratory fitness and muscle strength, respectively.

\section{$\mathrm{VO}_{2}$ peak test}

Each subject warmed up on a treadmill (4Front, Woodway, Waukesha, WI, USA) by jogging at a self-selected speed $(5-9 \mathrm{~km} / \mathrm{h})$, at $1 \%$ incline for $10 \mathrm{~min}$. This was followed by $5 \mathrm{~min}$ rest before commencing the maximal aerobic test. The starting speed was $10 \mathrm{~km} / \mathrm{h}$ and increased by $1 \mathrm{~km} / \mathrm{h}$ every $3 \mathrm{~min}$. Metabolic gas exchange was monitored continuously with a metabolic cart (Parvomedics TrueOne 2400, Sandy, UT, USA). Heart rate was monitored continuously with a heart rate monitor (Polar RS800CX, City, Finland) and ratings of perceived exertion (RPE) was determined during the last $15 \mathrm{~s}$ of each stage. The test was terminated upon volitional fatigue. Subjects were considered to have achieved their maximal aerobic capacity if any three of the following criteria were met:

1) Age-predicted maximal heart rate (220 - age)

2) Respiratory exchange ratio (RER) of $>1.1$

3) Volitional fatigue

4) Rating of perceived exertion (RPE) $>17$ (6-20 point scale)

\section{Muscular endurance test}

Each subject rested for 20 min after the $\mathrm{VO}_{2}$ peak test. Thereafter, he performed a 10-repetition maximum (10RM) test of the following exercises in sequential order: bench press, shoulder row and squat. The bench press and squats were performed with an Olympic barbell, and the shoulder row was performed using dumbbells. When the subject was able to complete more than 10 repetitions of each exercise, he was given a 5-min break before performing another round of 10 repetitions with a heavier weight. The final 10-RM for each subject would be the heaviest weight lifted for 10 repetitions with proper form.

\section{Exercise training protocol}

One week after baseline testing, subjects were prescribed an exercise training protocol spanning 3 consecutive weeks, with 3 consecutive days of training per week (Fig. 1). Days 1,4 , and 7 represent the first day of each week of exercise training, whereas Days 3, 6, and 9 represent the third and last day of each week's exercise session. Subjects also arrived $24 \mathrm{~h}$ after the last exercise training session in week 3 (Day 10), where a final blood and saliva sample were obtained with the subjects in a seated position $(24 H)$.

In week 1 , each subject warmed up by jogging on a treadmill for $5 \mathrm{~min}$. Thereafter, he ran at a speed corresponding to $80 \%$ of his maximal heart rate (pre-determined during $\mathrm{VO}_{2}$ peak testing) for $5 \mathrm{~min}$. This training intensity corresponded with the first ventilatory threshold $\left(\mathrm{VT}_{1}\right)$ and reflects an intensity of "somewhat hard" to "hard" on the RPE scale [31]. A 2 min rest was given after the treadmill run. After the rest, a series of resistance exercises (bench press, shoulder row, squats) was performed. The subject performed 10 repetitions of each resistance exercise with the weight set at $70 \%$ of $10-\mathrm{RM}$, and a $2 \mathrm{~min}$ rest between each exercise. This series of exercises (i.e. run + resistance exercise) constituted one set of the exercise protocol. Each subject completed a total of 4 sets of exercises. Water was consumed ad libitum for all sessions.

The treadmill speed and number of repetitions for the resistance exercises were increased by $10 \%$ each week. In addition, the rest interval between each exercise set was 


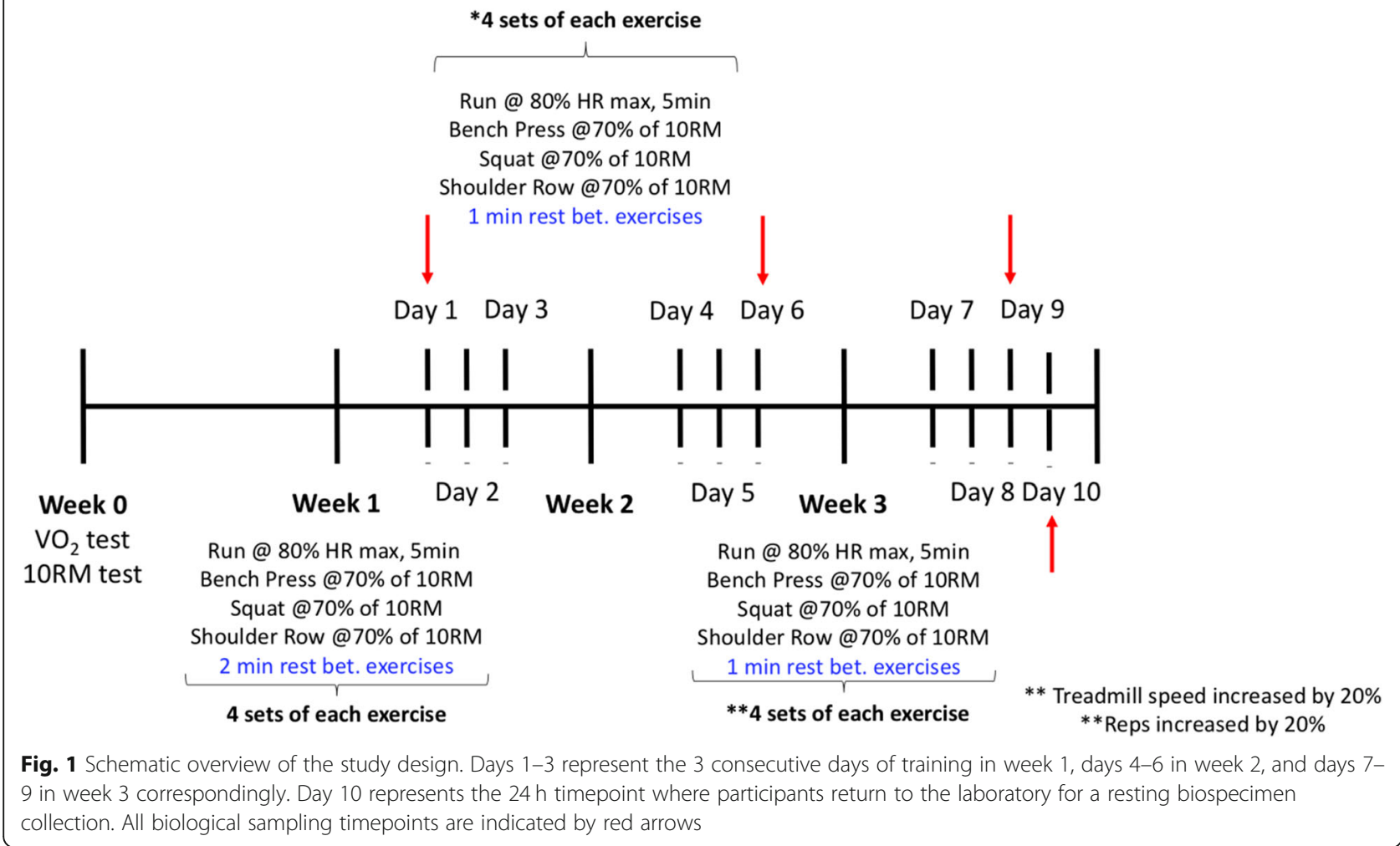

shortened from $2 \mathrm{~min}$ to $1 \mathrm{~min}$ in weeks 2 and 3 . We increased the training load weekly to prevent any adaptation to the prior week's exercise.

All exercises were performed under ambient conditions $\left(22-25^{\circ} \mathrm{C}\right)$ in the human performance laboratory at the Singapore Sports Institute.

\section{Heart rate and metabolic gas monitoring}

Heart rate was monitored continuously (Polar RS800CX, Polar Electro, City, Finland) from rest (seated for $5 \mathrm{~min}$ ) until the completion of each day's exercise session. Metabolic gases were monitored during the first and fourth set of treadmill running at each session. Heart rate $(\mathrm{HR}), \mathrm{VO}_{2}$ and RER were measured every minute for $5 \mathrm{~min}$ during the 1st and 4th sets of treadmill running. We report only the 1st and 4th set of metabolic data to track changes in exercise intensity during each training session from weeks $1-3$.

\section{Blood sampling and bioassays}

Blood was obtained from the antecubital vein on day 1 (first training day of week 1), day 6 (last training day of week 2), day 9 (last training day of week 3 ) and day 10 (24 $\mathrm{h}$ recovery). On days 1, 6 and 9, blood was drawn after 5 min of seated rest (Pre), immediately after exercise (Post) and after $30 \mathrm{~min}$ of recovery $(30 \mathrm{~min})$. Blood was collected into $\mathrm{K}_{3} \mathrm{EDTA}$ vacutainer tubes (Vacuette, Greiner BioOne, Austria). Tubes were centrifuged at $2000 \mathrm{rpm}$ for 10 min at $25^{\circ} \mathrm{C}$ and plasma samples were extracted immediately and stored on ice, before samples were transported back to DSO National Laboratories within $6 \mathrm{~h}$. On day 10 $(24 \mathrm{~h})$, blood was drawn from the antecubital vein after the subject had been seated quietly for at least $5 \mathrm{~min}$.

All plasma samples were stored at $-80^{\circ} \mathrm{C}$ until subsequent analyses. EDTA blood for flow cytometry experiments were kept at room temperature for a maximum 6 $\mathrm{h}$ before analysis. We were unable to obtain blood from one subject at Post on day 9, hence all biomarker results were reported for six subjects.

\section{Alarmin assays}

Plasma samples were quantified using commercial ELISA kits for the following alarmins: HMGB1 (IBL, Germany), HSP70 (Cloud-Clone Corp, USA), S100A8/A9 (BioVendor, Czech Republic) and soluble receptor advanced glycation end product (sRAGE) (Abcam, U.K). Assays were performed according to manufacturers' instructions. Experiments for each alarmin were repeated at least once, 

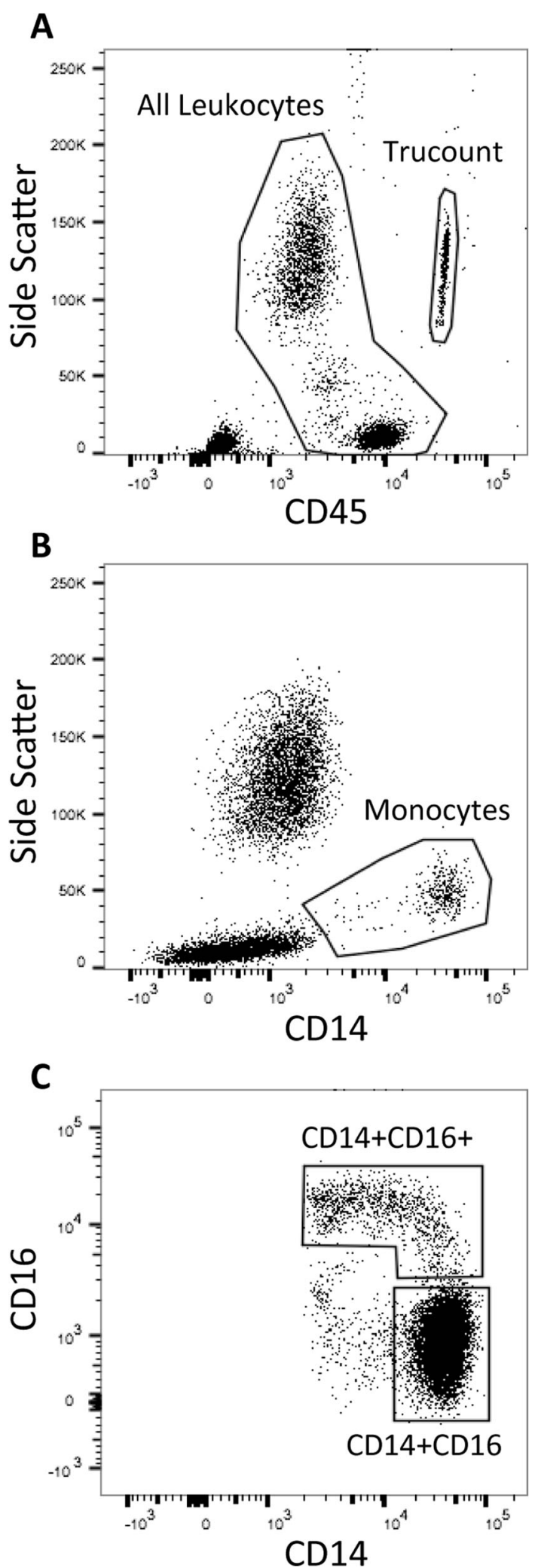

Fig. 2 Multicolor flow cytometric analyses of absolute cell count in whole blood. All Trucount beads and all leukocytes represented as CD45 were gated in (a). Total monocytes were gated on CD45 leukocytes as shown in (b). The CD14 ${ }^{+} \mathrm{CD} 16^{-}$and $\mathrm{CD} 14^{+} \mathrm{CD} 16^{+}$monocyte subsets were further gated from the monocyte population as shown in (c) 
except for HSP70, which was performed once. Subject samples were randomly assayed in duplicates, with intraassay coefficients of variation (CV) as follows: HMGB1 (9.6, 8.6\%), S100A8/A9 (9.7, 3.5\%), sRAGE (8.7, 6.5\%), HSP70 (6.3\%). The assay sensitivity of each kit was: $0.2 \mathrm{ng} /$ $\mathrm{mL}$ (HMGB1), $0.22 \mathrm{ng} / \mathrm{mL}$ (S100A8/A9), < $3 \mathrm{pg} / \mathrm{mL}$ (sRAGE), $<1.25 \mathrm{ng} / \mathrm{mL}$ (HSP70). Plasma concentrations of the alarmins were quantified with a microplate reader (Spectrostar Nano, BMG Lab Tech, City, Country).

\section{Multiplex cytokine and chemokine assays}

Cytokines (IL-10, IFN- $\gamma$ ) and chemokines (IL-8, MCP-1) were quantified using custom-made ProcartaPlex ${ }^{\circ}$ kits (Affymetrix Inc., City and/or State, U.S.A). The magnetic beads were quantified using a Luminex ${ }^{\circ} 200$ reader (Bio $\mathrm{Rad}$, U.S.A) with the MasterPlex ${ }^{\circ}$ CT software (v1.0) with the following settings: i) sample size: $50 \mu \mathrm{L}$, ii) DD gate: 5000 - 25,000, iii) timeout: $45 \mathrm{~s}$, iv) bead event: 100. Data analysis was performed with the MasterPlex ${ }^{\circ}$ QT software (v2.0) with logistic 4-point weighting for standard curve fitting. Endogenous concentrations of biomarkers in the sample were determined from this standard curve. The assay sensitivity of each biomarker of interest was: $2.71 \mathrm{pg} / \mathrm{mL}$ (IL-8), $2.49 \mathrm{pg} / \mathrm{mL}$ (IL-10), 11 $\mathrm{pg} / \mathrm{mL}(\mathrm{IFN}-\gamma)$, and $1.29 \mathrm{pg} / \mathrm{mL}$ (MCP-1).

\section{Quantification of monocyte subsets}

Absolute cell counts were assessed using a singleplatform lyse-no-wash and flow count bead procedure [32]. Briefly, $100 \mu \mathrm{L}$ of EDTA whole blood were added by reverse pipetting to $\mathrm{BD}$ TruCOUNT ${ }^{\mathrm{m} m}$ tubes (BD Biosciences, City and/or State, USA) and incubated for $15 \mathrm{~min}$ at room temperature (RT) with the following monoclonal antibodies: CD14, CD16 and CD45, conjugated to anti-Allophycocyanin (APC), Phycoerythrin $(\mathrm{PE})$ and Fluorescein isothiocyanate (FITC), respectively. Erythrocytes were lysed with $450 \mu \mathrm{L}$ of $1 x$ FACS lysing solution per tube, vortexed and incubated in the dark at RT for 15 min before acquisition with the FACS Canto II flow cytometer (Becton Dickinson, City and/or State, USA). Compensation was adjusted using three singlestain on a control sample. A control sample was obtained from a healthy male volunteer who was not part of the study, under fasted conditions. TruCount beads, $\mathrm{CD} 45^{+}, \mathrm{CD} 14^{+} \mathrm{CD} 16^{-}$and $\mathrm{CD} 14^{+} \mathrm{CD} 16^{+}$monocyte cell populations were gated with the FACS diva software (version 6.1.3). Acquisition was set at 10,000 counts in the $\mathrm{CD} 14^{+} 16^{-}$monocytes gate (Fig. 2) and the number of events recorded was used to calculate the absolute cell number according to the equation: (number of events in region containing cell/number of events in absolute count bead region) $\mathrm{x}$ (number of beads per test/test volume).
Table 1 Descriptive data of subjects

\begin{tabular}{ll}
\hline Parameters & Mean \pm SD \\
\hline Age (yrs) & $24.9 \pm 2$ \\
Body mass (kg) & $70.9 \pm 4.0$ \\
Height (cm) & $177.1 \pm 4.7$ \\
BMI & $22.6 \pm 1.6$ \\
Habitual physical activity (METS-min/wk) & $503.4 \pm 237.5$ \\
VO$_{2}$ peak (mL/kg/min) & $48.7 \pm 4.4$ \\
10-RM (kg) Bench press & $44.3 \pm 18.2$ \\
10-RM (kg) Squat & $55.0 \pm 46.9$ \\
10-RM (kg) Row & $24.6 \pm 7$ \\
Daily Caloric Intake (kcal) & $1798.0 \pm 236.2$
\end{tabular}

Baseline characteristics of the subjects (mean \pm SD) for anthropometric profiles, habitual physical activity patterns, cardiovascular fitness, strength and caloric intake

\section{Plasma creatine kinase activity}

The enzymatic activity of creatine kinase in plasma was tested with a commercial kit (ABNOVA, City, Taiwan) and plasma concentrations were quantified with a microplate reader (Spectrostar Nano, BMG Lab Tech, City, Country) according to the manufacturer's instructions.

\section{Salivary cortisol assays}

Saliva samples were collected by passive drooling into cryovials (Salimetrics ${ }^{\circ}$, Carlsbad, CA, USA) on the same days as phlebotomy: days 1, 6, 9 and 10. Samples were stored at $4{ }^{\circ} \mathrm{C}$ and transported to DSO National Laboratories within $6 \mathrm{~h}$ and stored in aliquots at $-80^{\circ} \mathrm{C}$ until further analyses. Salivary cortisol concentrations were detected with a cortisol ELISA kit (IBL, City, Germany) and quantified with a microplate reader (Spectrostar Nano, BMG Lab Tech, City, Country) according to the manufacturer's instructions.

\section{Statistics}

Two sets of metabolic data ( $\mathrm{HR}$ and $\left.\mathrm{VO}^{2}\right)$ were collected daily from the 1st and 4th set of treadmill running. A oneway repeated measures ANOVA was used to determine significant differences in mean $\mathrm{HR}$ and $\mathrm{VO}_{2}$ during 3 weeks of training. A 2-way repeated measures ANOVA was used to determine the effects of: i) increasing exercise intensity (weeks 1, 2 and 3) and ii) time (Pre, Post, $30 \mathrm{~min}$ ) on plasma concentration of biomarkers. When main effects for either intensity, time or interaction were statistically significant $(P<0.05)$, post hoc Tukey's multiple correction testing was used to assess mean differences within factors. A paired $t$ test was used to determine mean differences in biomarker concentrations between Pre (Day 1, week 1) and $24 H$ (Day 10 , week 3$)$. To determine the effect sizes $\left(\eta^{2}\right)$ of exercise training on alarmin response, sum of squares was divided over the total sum of squares. Effect sizes of $\eta^{2} \sim 0.2, \eta^{2} \sim$ 0.5 and $\eta^{2} \sim 0.8$ were considered "small", "medium" and 
Table 2 Training parameters of the subjects

\begin{tabular}{|c|c|c|c|}
\hline Parameters & Week 1 & Week 2 & Week 3 \\
\hline Speed (km/h) & $9.7 \pm 1.0(71.2 \%)$ & $10.7 \pm 1.0(78.5 \%)$ & $11.7 \pm 1.0(85.9 \%)$ \\
\hline Bench press (kg) & $27.2 \pm 15.9(52.6 \%)$ & $27.2 \pm 1(50.8 \%)$ & $27.2 \pm 15.9(49.1 \%)$ \\
\hline Squat (kg) & $34.7 \pm 32.5(52.1 \%)$ & $34.7 \pm 32.5(50.3 \%)$ & $34.7 \pm 32.5(48.6 \%)$ \\
\hline Row (kg) & $17.7 \pm 4.9(53.1 \%)$ & $17.7 \pm 4.9(51.3 \%)$ & $17.7 \pm 4.9(49.6 \%)$ \\
\hline HR set 1 (bpm)* & $149.9 \pm 6.7(77.7 \%)^{1,2}$ & $158.3 \pm 6.4(82.0 \%)^{1}$ & $163.8 \pm 5.6(84.9 \%)^{2}$ \\
\hline HR set $4(\mathrm{bpm})^{* *}$ & $160.3 \pm 5.2(82.0 \%)^{3,4}$ & $171.5 \pm 6.9(88.6 \%)^{3}$ & $177.0 \pm 8.4(91.9 \%)^{4}$ \\
\hline $\mathrm{VO}_{2}$ set $1(\mathrm{~mL} / \mathrm{kg} / \mathrm{min})^{\S}$ & $33.2 \pm 2.3(68.1 \%)^{5}$ & $37.3 \pm 4.7(76.6 \%)$ & $40.6 \pm 3.6(82.5 \%)^{5}$ \\
\hline $\mathrm{VO}_{2}$ set $4(\mathrm{~mL} / \mathrm{kg} / \mathrm{min})^{\dagger}$ & $34.1 \pm 3.9(70.1 \%)^{6}$ & $39.2 \pm 5.1(80.6 \%)$ & $42.1 \pm 4.7(85.4 \%)^{6}$ \\
\hline RER set 1 & $0.96 \pm 0.04$ & $0.99 \pm 0.05$ & $1.03 \pm 0.06$ \\
\hline RER set 4 & $0.90 \pm 0.04$ & $0.94 \pm 0.05$ & $0.97 \pm 0.05$ \\
\hline RPE set 1 & $11.4 \pm 1.7$ & $12.7 \pm 1.9$ & $13.8 \pm 1.8$ \\
\hline RPE set 4 & $12.7 \pm 2.0$ & $14.5 \pm 1.9$ & $15.7 \pm 1.8$ \\
\hline
\end{tabular}

Running speed (\% of maximal aerobic speed), weight (\% of 1-RM) and physiological responses during 3 weeks of increasing workload (HR - heart rate bpm (\% of HR max); $\mathrm{VO}_{2}$ - oxygen uptake ( $\mathrm{mL} / \mathrm{kg} / \mathrm{min}, \% \mathrm{VO}_{2}$ peak); $\mathrm{RER}$ - respiratory exchange ratio; $\mathrm{RPE}$ - rating of perceived exertion). The metabolic parameters were recorded every minute and averaged for the $5 \mathrm{~min}$ of treadmill running for the $1 \mathrm{st}$ and 4th exercise set. RPE was recorded during the last $15 \mathrm{~s}$ per minute of each running bout * Statistical significance of main effects between weeks: $P<0.0001$

1 Tukey's multiple comparison between week 1 and 2: $P=0.0038$

${ }^{2}$ Tukey's multiple comparison between week 1 and $3: P<0.0001$

** Statistical significance of main effects between weeks: $P=0.0002$

${ }^{3}$ Tukey's multiple comparison between week 1 and 2: $P=0.0054$

${ }^{4}$ Tukey's multiple comparison between week 1 and 3: $P=0.0002$

${ }^{\S}$ Statistical significance of main effects between weeks: $P=0.0002$

${ }^{5}$ Tukey's multiple comparison between week 1 and 3: $P=0.0011$

${ }^{+}$Statistical significance of main effects between weeks: $P=0.0028$

${ }^{6}$ Tukey's multiple comparison between week 1 and 3: $P=0.0043$

"large", respectively [33]. Linear regression was used to assess the relationship between absolute or relative changes $(\Delta)$ in exercise-induced alarmins with i) MCP-1 and ii) monocyte subsets. Statistical significance was set at $P<$ 0.05. Analyses were performed with Graphpad Prism (version 6.0.5) with data presented as means \pm SD.

\section{Results}

The descriptive profiles of the subjects are shown in Table 1. The mean age of the subjects was $24.9 \pm 2$ yrs., with a range between 23 and 29 yrs. The mean BMI was $22.6 \pm 1.6$, and the mean $\mathrm{VO}_{2}$ peak was $48.7 \pm 4.4 \mathrm{~mL} / \mathrm{kg} / \mathrm{min}$.

\section{Physiological responses to exercise training}

The subjects completed all training sessions and the parameters are summarized in Table 2 . The treadmill speed in week 1 was $9.7 \pm 1.0 \mathrm{~km} / \mathrm{h}(71.2 \%$ of maximal speed; $\mathrm{V}_{\max }$ ) and the resistance training load was set at $27.2 \pm$ $15.9 \mathrm{~kg}$ (52.6\% of 1-RM) for Bench Press, $34.7 \pm 32.5 \mathrm{~kg}$ (52.1\% of $1-\mathrm{RM})$ for Squat and $17.7 \pm 4.9 \mathrm{~kg}(53.1 \%$ of 1 -

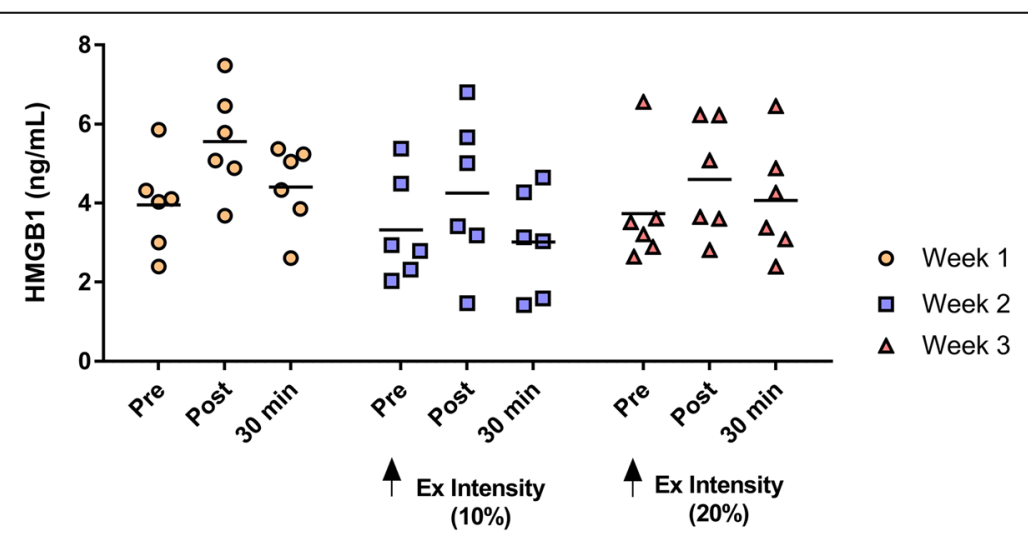

Fig. 3 Plasma [HMGB1] during 3 weeks of exercise training. Data showed a significant main effect of time $(P=0.028)$ but Post hoc Tukey's multiple testing did not show statistical significance in mean HMGB1 within each week. No significant main effect of intensity or interaction was detected $(P>0.05)$. Pre, Post and $30 \mathrm{~min}$ are timepoints of blood sampling before, immediately after, and 30 min after the exercise bout respectively 


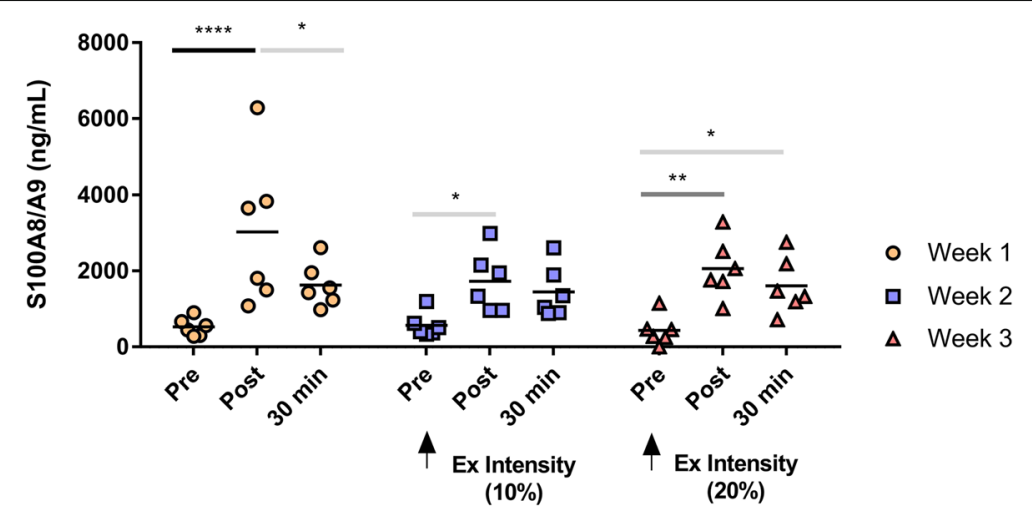

Fig. 4 Plasma [S100A8/A9] from individual participants during 3 weeks of exercise training. A main effect of time was observed $(P<0.0001)$. Post hoc Tukey's multiple comparison test within each week: ${ }^{*} P<0.05$, ${ }^{* *} P<0.001,{ }^{* * *} P<0.0001$

RM) for Row with 10 repetitions per set, for a total of 4 sets. Running speed was increased to $10.7 \pm 1.0 \mathrm{~km} / \mathrm{h}$ $\left(78.5 \%\right.$ of $\left.\mathrm{V}_{\max }\right)$ in week 2 and to $11.7 \pm 1.0 \mathrm{~km} / \mathrm{h}(85.9 \%$ of $\mathrm{V}_{\max }$ ) in week 3 . The number of repetitions for the resistance exercises were increased to 11 in week 2 and 12 in week 3 without changing the total weight lifted. This increase in repetitions reduced the \%1-RM to 50.8 and 49.1\% for Chest, 50.3 and $48.6 \%$ for Squat, 51.3 and $49.6 \%$ for Row in week 2 and 3, respectively.

Increases in running speed and resistance load from week 1 to week 3 resulted in an increase in physiological strain, with $\mathrm{HR}, \mathrm{VO}_{2}$ significantly increased between week 1 and week 3 . The subjects attained $82.0 \%$ of $\mathrm{HR}_{\max }$ and $70.1 \%$ of $\mathrm{VO}_{2}$ peak in week 1 and $88.6 \%$ of $\mathrm{HR}_{\max }$ and $80.6 \%$ of $\mathrm{VO}_{2 \text { peak }}$ in week 2 , respectively. These parameters were between the first and second ventilatory thresholds $\left(\mathrm{VT}_{1}\right.$ and $\left.\mathrm{VT}_{2}\right)$ during weeks 1 and 2, as indicated by RER $<1.0$. In week 3 , the subjects ran at $91.9 \%$ of $H_{\text {max }}$ and $85.4 \%$ of $\mathrm{VO}_{2}$ peak which indicated a workload above $\mathrm{VT}_{2}$ (RER > 1.0). RPE scores were elevated by $24 \%$, increasing from $12.7 \pm 2.0$ at week 1 to $15.7 \pm 1.8$ at week 3 .
Effects of exercise on plasma alarmins

Significant main effects of time were found for HMGB1 $\left(P=0.03, \eta^{2}=0.12\right)$ (Fig. 3), S100A8/A9 $\left(P<0.0001, \eta^{2}=\right.$ $0.42)$ (Fig. 4) and $\operatorname{HSP70}\left(P=0.0003, \eta^{2}=0.19\right)$ (Fig. 5) across the 3 weeks of exercise training, but not for sRAGE $\left(P=0.91, \eta^{2}=0.0025\right)$ (not shown). There was no significant main effect of intensity on any of the alarmin response to exercise. Post hoc analyses did not detect significant differences of time for HMGB1 within each week.

Post hoc Tukey's multiple testing demonstrated a 5.8$(P<0.0001), 2.5-(P<0.05)$ and 4.7 -fold $(P<0.01)$ increase in plasma S100A8/A9 at Post compared with Pre in week $1(3031 \pm 1964 \mathrm{ng} / \mathrm{mL}$ vs. $529.4 \pm 234.3 \mathrm{ng} / \mathrm{mL})$, week 2 $(1728 \pm 793 \mathrm{ng} / \mathrm{mL}$ vs. $572.8 \pm 321.6 \mathrm{ng} / \mathrm{mL})$ and week 3 $(2061.0 \pm 776.5 \mathrm{ng} / \mathrm{mL}$ vs. $434.4 \pm 391.7 \mathrm{ng} / \mathrm{mL})$, respectively (Fig. 4). In week 3, plasma S100A8/A9 concentrations was 3.7-fold higher at $30 \mathrm{~min}$ compared with Pre $(P<0.05$; $1609.0 \pm 737.3 \mathrm{ng} / \mathrm{mL}$ vs. $434.4 \pm 391.7 \mathrm{ng} / \mathrm{mL})$.

Plasma HSP70 increased 1.9- $(P<0.01)$ and 1.5 -folds $(P<0.05)$ at Post, compared with Pre, in week $1(9.17 \pm$ $3.06 \mathrm{ng} / \mathrm{mL}$ vs. $4.96 \pm 1.46 \mathrm{ng} / \mathrm{mL})$ and week $3(9.30 \pm 4.14$

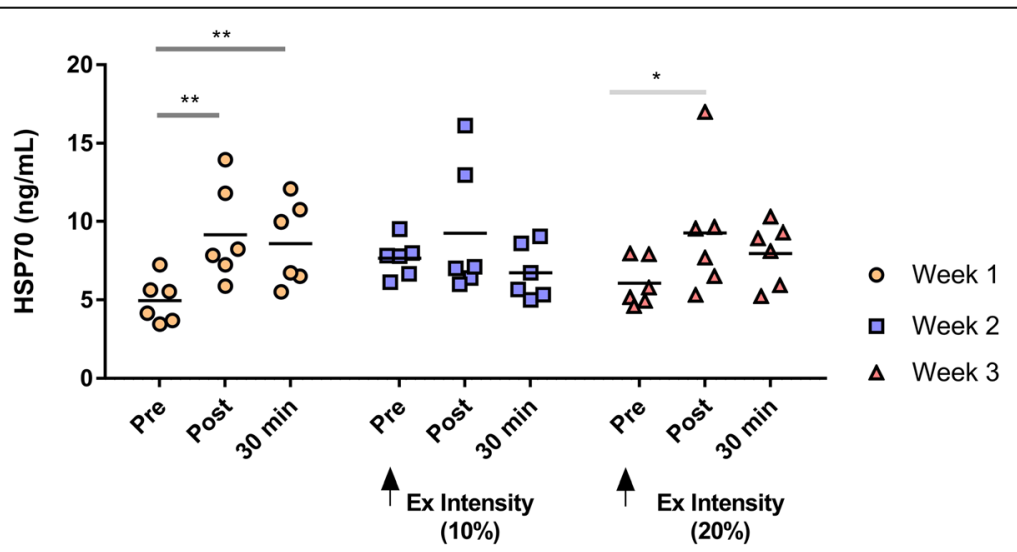

Fig. 5 Plasma [HSP70] during 3 weeks of exercise training $(N=6)$. A significant main effect of time was observed $(P=0.0003)$. Post hoc Tukey's test was used to compare mean HSP70 between timepoints within each week. ${ }^{*} P<0.05$ and ${ }^{* *} P<0.01$ 


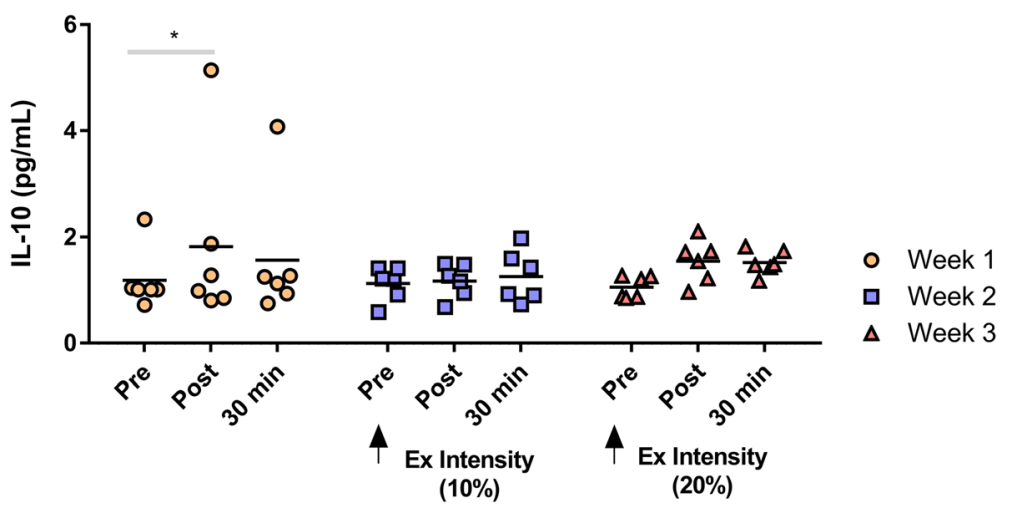

Fig. 6 Plasma [IL-10] during 3 weeks of exercise training $(N=6)$. A main effect of time was detected $(P=0.01)$. Post hoc Tukey's multiple testing further showed significant differences in plasma IL-10 at Pre vs. Post in week $1 .{ }^{*} P<0.05$

$\mathrm{ng} / \mathrm{mL}$ vs. $6.07 \pm 1.51 \mathrm{ng} / \mathrm{mL}$ ) respectively, as depicted in Fig. 3. Plasma HSP70 remained elevated by 1.4 -fold at 30 min, compared with Pre, in week $1 \quad(P<0.01$; $6.75 \pm 1.74 \mathrm{ng} / \mathrm{mL}$ vs. $4.96 \pm 1.46 \mathrm{ng} / \mathrm{mL})$.

\section{Effects of exercise on plasma cytokines and chemokines} A significant main effect of time was observed for IL-10 (Fig. 6, $P=0.01, \eta^{2}=0.053$ ). Post hoc Tukey's multiple testing showed a 1.5-fold increase in IL-10 from Pre to Post in week 1 . There was also a significant effect of time and interaction for MCP-1 (Fig. 7, $P=0.0003 ; \eta^{2}=0.073, P=0.05$ ). Post hoc Tukey's multiple testing demonstrated a 1.2-fold increase in MCP-1 from Pre to Post, and from Pre to 30 min, both in week $3(P<0.01)$. There was no significant effect of intensity for either IL-10 or MCP-1. As well, there were no significant main effects of either intensity or time for IFN- $\gamma(P>0.05$, not shown) or IL-8 $(P=0.06)$. However, there was a significant main effect of interaction for IL-8 $(P=0.04)$, with data from week 3 showing elevated concentrations of this chemokine from Pre to Post $(P=0.0054)$, and Pre to $30 \mathrm{~min}$ (Fig. 8; $P=0.0076$ ).
Correlations between exercise-induced alarmins and MCP-1 $\triangle \mathrm{HMGB1}$ and $\triangle \mathrm{HSP} 70$ correlated positively with $\triangle \mathrm{MCP}-$ 1 at all timepoints, as depicted in Fig. 9. A stronger linear relationship was observed for $\triangle \mathrm{MCP}-1$ with $\triangle \mathrm{HSP} 70$ $($ slope $=0.9711)$ than with $\triangle$ HMGB1 $($ slope $=0.6574)$.

Effects of exercise on total leukocytes and monocyte subsets A significant main effect of time was observed for mean cell counts of all leukocytes $\left(\mathrm{CD} 45^{+} ; P<0.0001, \eta^{2}=\right.$ 0.30) (Fig. 10). The effect of exercise in enhancing leukocyte trafficking immediately after a bout of exercise was evident during the 3-week study. Post hoc Tukey's multiple testing demonstrated a 1.2- and 1.6-fold increase at Post relative to Pre for weeks $1(9124 \pm 1826$ cells $/ \mu \mathrm{L}$ vs. $7377 \pm 1597$ cells $/ \mu \mathrm{L})$ and $3(10,511 \pm 2444$ cells $/ \mu \mathrm{L}$ vs. $6492 \pm 1158$ cells $/ \mu \mathrm{L})$, respectively. Exerciseinduced leukocytosis was relatively mild in week 2 $(6179 \pm 2071$ cells $/ \mu \mathrm{L}$ vs. $5925 \pm 1210$ cells $/ \mu \mathrm{L})$, with a 4\% increase at Post relative to Pre.

There was a significant effect of time on the response of $\mathrm{CD}_{1} 4^{+} \mathrm{CD} 16^{-}$monocytes $\quad\left(P<0.0001, \quad \eta^{2}=0.17\right)$

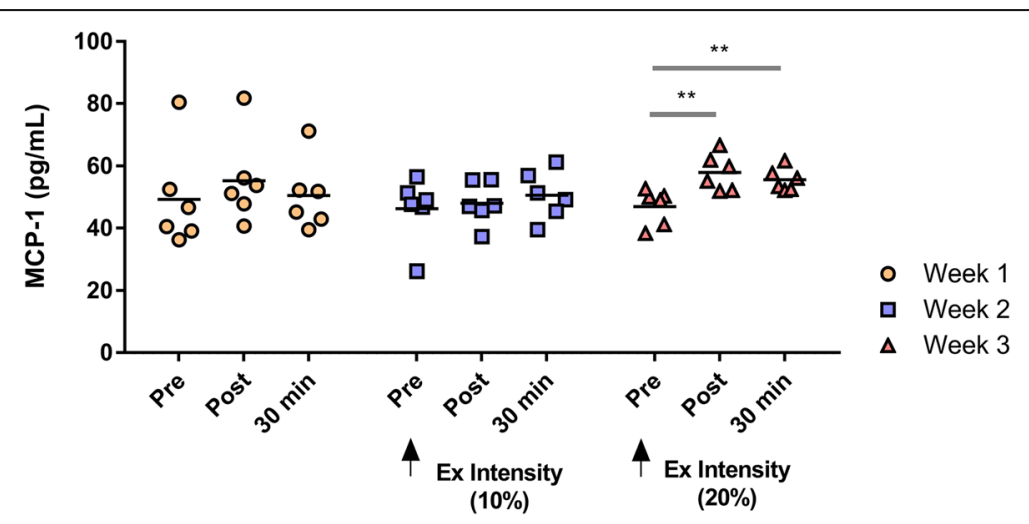

Fig. 7 Plasma $[M C P-1]$ during 3 weeks of exercise training $(N=6)$. Significant main effects of time $(P=0.0003)$ and interaction $(P=0.05)$ were detected. Post hoc Tukey's multiple testing showed significant differences in week 3 , between Pre and Post $(P<0.01)$ and between Pre and 30 min $(P<0.01)$. ${ }^{* *} P<0.01$. No significant main effect of intensity was observed $(P>0.05)$ 


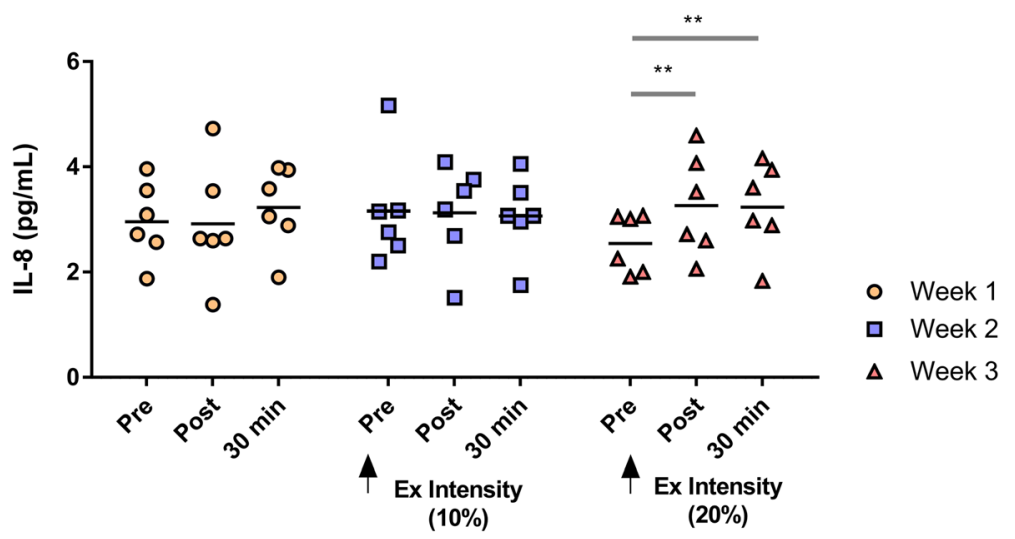

Fig. 8 Plasma [IL-8] during 3 weeks of exercise training $(N=6)$. A significant main effect of interaction (time $x$ intensity) was observed $(P=0.04)$. Post hoc Tukey's multiple testing showed significant differences in week 3 , between Pre and Post $(P<0.01)$, and between Pre and 30 min $(P<0.01) .{ }^{* *} P<0.01$

(Fig. 11) and $\mathrm{CD} 14^{+} \mathrm{CD} 16^{+}$monocytes $\left(P<0.0001, \eta^{2}=\right.$ 0.20) (Fig. 12). Furthermore, a significant interaction (time $\mathrm{x}$ intensity) was observed for $\mathrm{CD} 14^{+} \mathrm{CD} 16^{+}$monocytes $(P=0.02)$. Post hoc Tukey's multiple testing demonstrated that an exercise-induced monocytosis was evident for both subsets. $\mathrm{CD} 14^{+} \mathrm{CD} 16^{-}$monocytes were increased by 1.2-, 1.3- and 1.5-fold from Pre to Post in week $1(486 \pm 109$ cells $/ \mu \mathrm{L}$ vs. $587 \pm 152$ cells $/ \mu \mathrm{L}, P<$ $0.05), 2(381 \pm 76$ cells $/ \mu \mathrm{L}$ vs. $491 \pm 130$ cells $/ \mu \mathrm{L}, P<$ $0.05)$ and $3(419 \pm 131$ cells $/ \mu \mathrm{L}$ vs. $610 \pm 174$ cells $/ \mu \mathrm{L}$, $P<0.0001)$, respectively.

$\mathrm{CD} 14^{+} \mathrm{CD} 16^{+}$monocytes also showed a similar response to exercise, increasing by 1.7 -fold from Pre to Post in week $2(25 \pm 16$ cells/ $\mu \mathrm{L}$ vs. $41 \pm 23$ cells $/ \mu \mathrm{L}, P<$ $0.005)$ and 1.5-fold from Pre to Post in week 3 (31 \pm 21 cells $/ \mu \mathrm{L}$ vs. $47 \pm 19$ cells $/ \mu \mathrm{L}, P<0.01)$. In addition, there was a $50 \%$ reduction in $\mathrm{CD} 14^{+} \mathrm{CD} 16^{+}$monocytes at 30 min from Pre $(31 \pm 21$ cells $/ \mu \mathrm{L}$ vs. $16 \pm 9$ cells $/ \mu \mathrm{L}, P<$ $0.01)$ in week 3.

\section{Correlations between exercise-induced alarmins and monocytes}

Of all the alarmins tested, only HMGB1 correlated significantly with $\mathrm{CD} 14^{+} \mathrm{CD} 16^{-}$monocytes across 3 weeks of training (Fig. 13).

\section{Effects of exercise on plasma creatine kinase and salivary cortisol}

Mean plasma creatine kinase activity did not differ significantly with respect to time, intensity or interaction during the study $(P>0.05$, Week $1: 31.51 \pm 1.62 \mathrm{U} / \mathrm{L}$; Week 2: $35.73 \pm 3.61 \mathrm{U} / \mathrm{L}$; Week 3: $44.93 \pm 13.38 \mathrm{U} / \mathrm{L}$ ). Whereas main effects were not significant, a significant interaction effect (time $\mathrm{x}$ intensity) was observed for salivary cortisol $(P=0.01$, Week $1: 0.88 \pm 0.51 \mu \mathrm{g} / \mathrm{dL}$; Week 2: $1.14 \pm 0.15 \mu \mathrm{g} / \mathrm{dL}$; Week 3: $1.36 \pm 0.34 \mu \mathrm{g} / \mathrm{dL}$ ), with post hoc Tukey's testing showing decreased concentrations of cortisol at Post and $30 \mathrm{~min}$, relative to Pre.

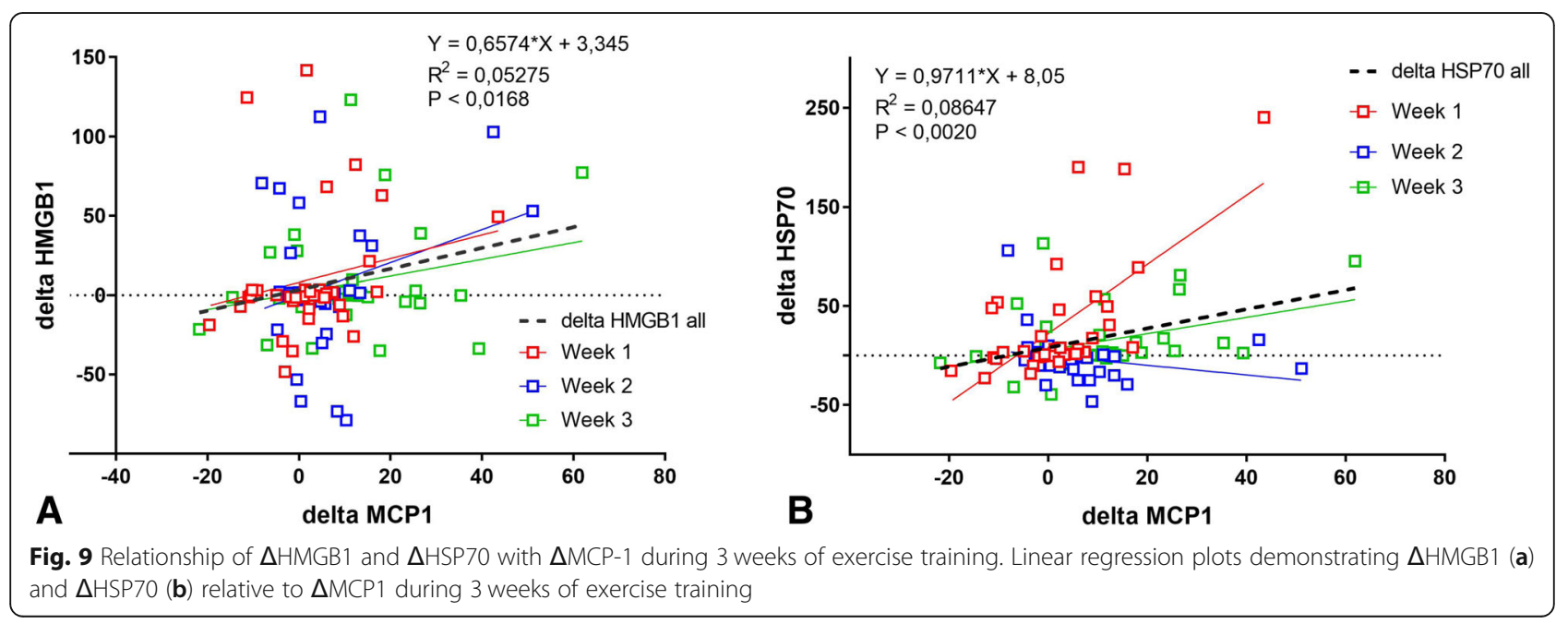




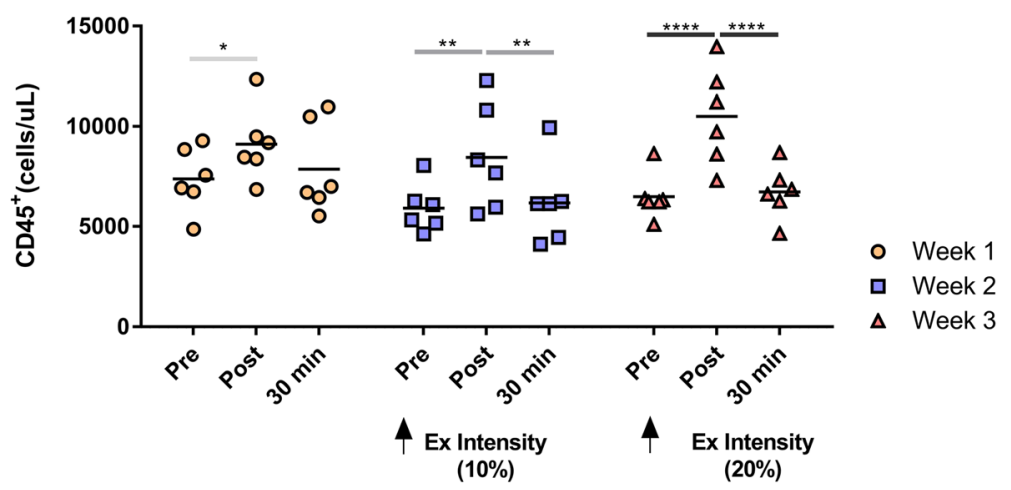

Fig. 10 Circulating numbers of $C D 45^{+}$leukocytes during 3 weeks of exercise training ( $N=6$ ). Significant effect of time was detected $(P<0.0001)$. Post hoc Tukey's adjusted significance: ${ }^{*} P<0.05,{ }^{* *} P<0.01$, ${ }^{* * *} P<0.0001$. No significant main effect of intensity or interaction was observed $(P>0.05)$

Main effects of time or intensity for salivary cortisol were not statistically significant $(P>0.05)$.

\section{Discussion}

The novelty of our study is that this is the first study to measure multiple alarmins after repeated bouts of exercise with increasing intensity across 3 consecutive weeks. Furthermore, the increase in circulating alarmins (HMGB1, S100A8/A9, HSP70) varied temporally with one another and occurred in the absence of, or minimal corresponding changes in traditional cytokine markers of exercise-induced stress, such as IFN- $\gamma$, IL-8 and IL10. As well, concentrations of plasma creatine kinase, a commonly used marker of skeletal muscle damage, did not show significant differences across time. We discuss these findings in detail in the subsequent sections.

\section{Concurrent exercise training model}

The combined training paradigm comprised multiple sets of short bouts of treadmill running at an initial $80 \%$ of maximal heart rate, as well as resistance exercises at approximately $50 \%$ of 1 -RM, targeting major muscle groups and increasing workload by 10 and $20 \%$ in weeks 2 and 3 respectively. During treadmill running, subjects used mainly energetic systems between $\mathrm{VT}_{1}$ and $\mathrm{VT}_{2}$ [31] for the first 2 weeks and switched to slightly above $\mathrm{VT}_{2}$ in week 3 , suggesting the subjects were more reliant on anaerobic energetic systems during week 3 . The exercise model in the present study closely resembles highintensity interval exercises such as Crossfit ${ }^{\circledR}$ programs [34] that are gaining popularity with the general public.

Intense aerobic and resistance exercise training increases systemic alarmins without perturbing systemic creatine kinase

An interesting outcome in the present study is the dynamic responses of alarmins in the apparent absence of creatine kinase perturbation. Increased circulating creatine kinase as a consequence of skeletal muscle damage elicited by eccentric exercise typically occurs several hours after an exercise bout, with a peak around 5-7 days [35]. The recovery period in this study was $\sim 24 \mathrm{~h}$ on training days,

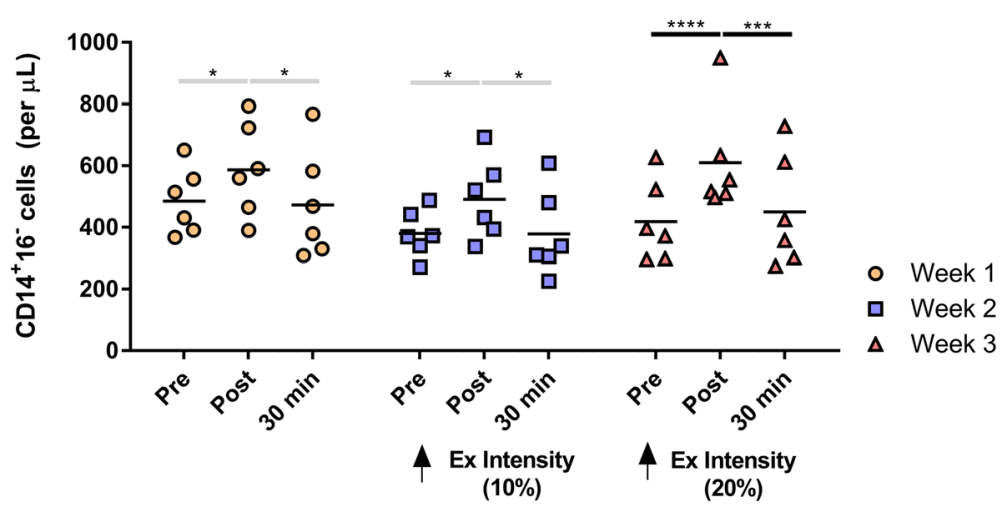

Fig. 11 Circulating numbers of $C D 14^{+} \mathrm{CD} 16^{-}$monocytes during 3 weeks of exercise training $(N=6)$. Significant effect of time was detected $(P<0.0001)$. Post hoc significance using Tukey's multiple test: ${ }^{*} P<0.05,{ }^{* * *} P<0.001,{ }^{* * * *} P<0.0001$. No significant main effect of intensity or interaction was observed $(P>0.05)$ 


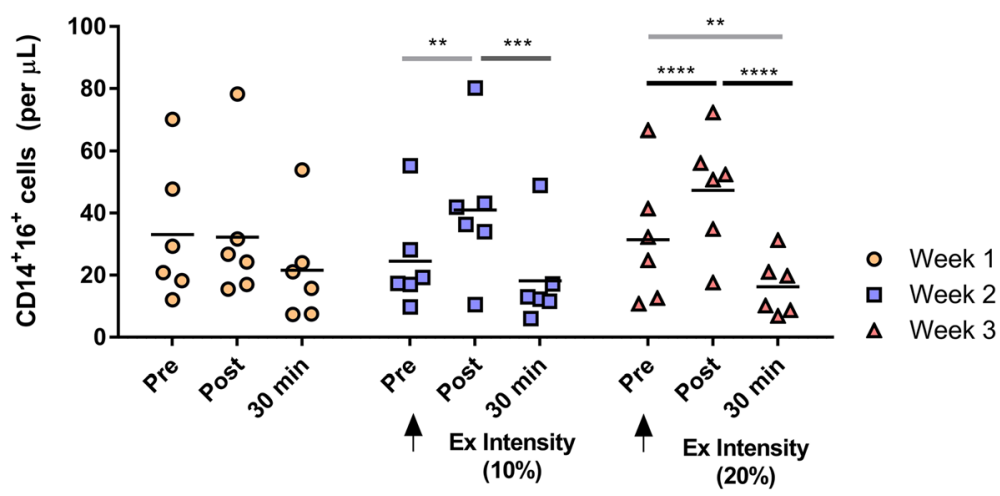

Fig. 12 Circulating numbers of $\mathrm{CD} 14^{+} \mathrm{CD} 16^{+}$monocytes during 3 weeks of exercise training $(N=6)$. Significant effect of time $(P<0.0001)$ and interaction (time $\mathrm{x}$ intensity; $P=0.02$ ) were detected. Post hoc significance using Tukey's multiple test: ${ }^{* *} P<0.01,{ }^{* * *} P<0.001,{ }^{* * * *} P<0.0001$. No significant main effect of intensity was observed $(P>0.05)$

with biological samples collected on the $3 \mathrm{rd}(72 \mathrm{~h})$ day in week 2 and 3. Despite this, no significant changes in creatine kinase activity were observed across the study period, suggesting that skeletal muscle damage may be minimal. Hence, the fact that alarmins were induced with exercise in the absence of muscle damage may indicate either a subtler response to cellular stress or a systemic response to muscle contraction, increased body temperature and tissue hypoxia, and increased metabolic stress.

\section{Exercise-induced alarmin release is modulated by exercise duration, intensity and type}

The increase in systemic HMGB1 during 3 weeks of exercise training ranged from 1.2- to 1.4-fold in the present study, and is much lower, compared with reports by Beiter et al. [14] and Bekos et al. [12]. Beiter et al. reported a 3-fold increase in plasma HMGB1 immediately after an exhaustive run $(5.0 \mathrm{ng} / \mathrm{mL})$, compared with resting concentrations $(1.5 \mathrm{ng} / \mathrm{mL})$. In the Bekos study,

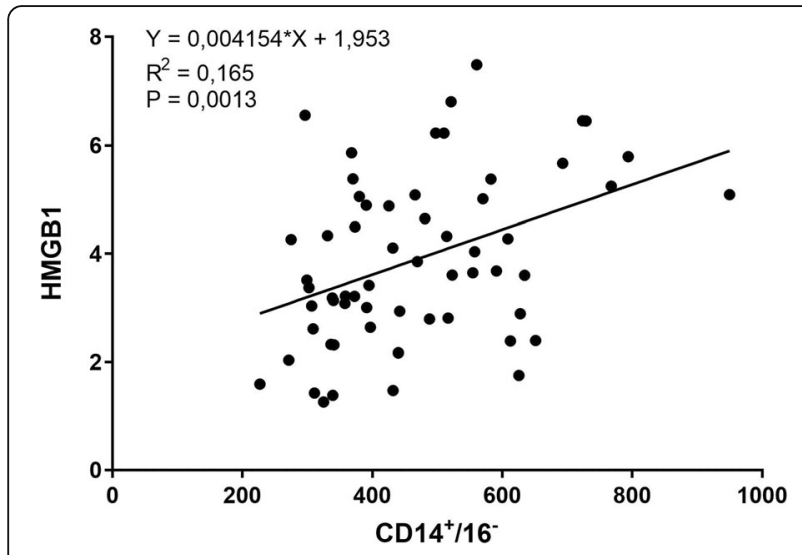

Fig. 13 Correlation between plasma HMGB1 with circulating $\mathrm{CD} 14^{+} \mathrm{CD} 16^{-}$monocytes during 3 weeks of exercise. HMGB1 showing a positive correlation with $\mathrm{CD} 14^{+} \mathrm{CD} 16^{-}$cell counts serum concentrations increased $\sim 1.5$-fold (half-marathon; $3.13 \pm 1.63 \mathrm{ng} / \mathrm{mL}$ to $4.78 \pm 2.1 \mathrm{ng} / \mathrm{mL}$ ) and $\sim 2.3$ fold (marathon; $2.58 \pm 1.58 \mathrm{ng} / \mathrm{mL}$ to $6.02 \pm 2.18 \mathrm{ng} / \mathrm{mL}$ ) after the respective races. These are fascinating comparisons, because they suggest that HMGB1 responds in a dose-dependent manner to the intensity of the exercise.

The outcomes in the present study for S100A8/A9 are similar with previous studies [18-20,36]. Fico et al. [18] demonstrated S100A8/A9 to be upregulated by $\sim 2$-fold with high-intensity interval cycling, whereas continuous cycle ergometry increased S100A8/A9 by $~ 5$-fold [19]. As well, Maharaj et al. [20] showed that a 30-min treadmill running at $75 \% \mathrm{VO}_{2}$ max elicited an $\sim 3$-fold increase in S100A8/A9. In our study, S100A8/A9 appeared to be most responsive to increases in weekly training load, compared with other alarmins, with a 5-fold increase in plasma concentrations at Post, compared with Pre $(P \leq 0.01)$ in the third week (Fig. 4). The magnitude of the increase in circulating S100A8/A9 may depend on exercise intensity and duration, or the number of muscle fibers recruited, given that the concentrations of this alarmin were not increased with calf-raise exercise [21], whereas our subjects were performing whole body exercises with the strength exercises and treadmill runs. Alternatively, it cannot be ruled out that the exercise-induced release of the alarmins could be tissue-specific. Contracting skeletal muscle can secrete S100A8/A9 per se [19], with transcript expressions increasing by 5 -fold in skeletal muscle after cycle ergometry [19].

Systemic elevation of HSP70 was observed during 3 weeks of exercise training, suggesting that increased concentrations of this alarmin may be necessary to facilitate protein degradation and folding, prevent cellular apoptosis and also to up-regulate innate and adaptive immunity [37]. Although it is possible that contracting skeletal muscle can secrete HSP70 [22] per se, the exercise-induced release of HSP72 into circulation precedes the increase in mRNA transcription in skeletal muscle [16], suggesting that the 
acute release of HSP70 into peripheral blood may have originated from other organs, such as the liver [17] or alternatively, HSP70 may be released from skeletal muscles and packaged within extracellular vesicles, such as exosomes [38], given their rapid appearance in plasma. However, since exosomal HSP70 was not isolated in the present study, this point remains speculative.

sRAGE was of interest in this study, as it binds extracellular HMGB1 and S100 proteins, and has been shown to be present in soluble form [35]. Exercise training in the present study appeared not to modulate changes in sRAGE concentration. This contrasted with previous reports, where high-intensity aerobic exercise training for 8 weeks increased plasma concentrations of sRAGE in sedentary men [34], and 3 months of aerobic exercise also enhanced plasma sRAGE in diabetic patients [5]. One explanation may be that 3 weeks of exercise with increasing workload was too short to induce similar effects as reported by others. Another possibility is that the subjects in this study were young, active men with no co-morbidities, which was different from the subjects recruited by Santilli et al. [34] and Choi et al. [5]. Another possibility for the discrepancy could be due to the combined energetic pathways (aerobic, anaerobic) of the exercise training program, which may be insufficient to modulate increased sRAGE release.

\section{Concurrent exercise training increased circulating monocyte subsets}

The role of $\mathrm{CD} 14^{+} \mathrm{CD} 16^{-}$and $\mathrm{CD} 14^{+} \mathrm{CD} 16^{+}$monocyte subsets in modulating alarmin and immune responses [11], as well as in tissue remodeling [3], was of interest, particularly in the context of intense exercise training. The results are generally consistent with the findings of others [20] in that acute exercise of moderate-to-high intensity mediates an increase in circulating $\mathrm{CD} 14^{+} \mathrm{CD} 16^{-}$and $\mathrm{CD} 14^{+} \mathrm{CD} 16^{+}$ monocytes. Exercise also increased $\mathrm{CD} 14^{+} \mathrm{CD} 16^{-}$monocytes from resting levels in all 3 weeks, whereas the elevation in $\mathrm{CD}_{14}{ }^{+} \mathrm{CD} 16^{+}$monocytes was seen only in week 2 and 3 (Fig. 12). The present findings differed from Leicht and co-authors [39] in that increases in both monocyte subset numbers occurred immediately after exercise, whereas Leicht et al. reported only a significant increase in $\mathrm{CD} 14^{+} \mathrm{CD} 16^{-}$monocytes but not $\mathrm{CD} 14^{+} \mathrm{CD} 16^{+}$monocytes, and only during a $2 \mathrm{~h}$ recovery from exercise. Significant changes were not detected immediately after exercise in their study. The exercise program in the present study involved both upper and lower body muscle groups, and thus the subjects could have experienced a higher oxygen cost of activity, which may coincide with greater recruitment of monocytes via increased secretion of epinephrine. This could then explain for the faster increase in appearance of the monocyte subsets.

The magnitude of $\mathrm{CD} 14^{+} \mathrm{CD} 16^{+}$monocyte responses to exercise and after recovery appears to be dependent on the intensity and duration of the exercise, with exerciseinduced catecholamines mobilizing $\mathrm{CD} 14^{+} \mathrm{CD} 16^{+}$monocytes [40]. The absence of a significant increase in $\mathrm{CD} 14^{+} \mathrm{CD} 16^{+}$monocytes in week 1 suggested that the prescribed exercise intensity was below the threshold needed to mobilize them from the marginal pool into the peripheral blood circulation, whereas the increase in this monocyte subset in weeks 2 and 3 suggested that an augmented stress response may have been responsible. Reduced numbers of circulating $\mathrm{CD} 14^{+} \mathrm{CD} 16^{+}$monocytes were observed below baseline levels during recovery $(30 \mathrm{~min})$ in week 3 , suggesting that some demargination of monocytes into tissues may have occurred post-exercise [40].

\section{Exercise-induced alarmin release is associated with increased circulating monocyte subsets}

Whether exercise training-induced changes in alarmins were associated with that in different monocyte subsets was of interest. To this extent, both HMGB1 and HSP70 demonstrated a positive correlation with MCP-1, with the case for HSP70 and monocyte recruitment appearing to be more sensitive to exercise intensity per se. Throughout the 3 weeks of exercise training, the regression slopes of $\triangle$ HSP70 relative to $\triangle \mathrm{MCP}-1$ decreased in week 2 and increased again in week 3 (Fig. 9b). Conversely, HMGB1 appears to be a generic modulator of exercise stress (Fig. 9a; all 3 linear regressions have similar slopes), although it appears to be a more specific inducer of $\mathrm{CD} 14^{+} \mathrm{CD} 16^{-}$ monocytes than the other alarmins (Fig. 13).

While cautious interpretation of these results is warranted, the present data suggest that the subjects experiencing greater metabolic stress or inflammation at various timepoints during the study may have increased circulating monocytes, particularly the $\mathrm{CD} 14^{+} \mathrm{CD} 16^{-}$ subset, and this may be related to the level of circulating alarmins. The temporal responses of each of these alarmins in the current study are complicated. It is known that HSP70 can inhibit both nuclear translocation of HMGB1 as well as HMGB1-induced release of pro-inflammatory cytokines in RAW264.7 macrophages [41, 42]. While speculative, we suggest that exercise-induced HMGB1 resulted in a corresponding response in increased HSP70 to dampen the inflammatory response [43]. The increased appearance of the $\mathrm{CD} 14^{+} \mathrm{CD} 16^{-}$subsets may be driven by the need to resolve tissue inflammation.

\section{Conclusion}

In this short-term training study, alarmins are released into systemic circulation by combined aerobic and resistance exercise, with their release and clearance differing temporally. Especially, increased concentrations of circulating alarmins (HMGB1, S100A8/A9, HSP70) occurred in the absence of, or minimal corresponding changes in traditional cytokine markers of exercise-induced stress 
and inflammation, such as IFN- $\gamma$, IL-8 and IL-10 as well as in muscle damage markers (e.g. creatine kinase). Further investigations are necessary to elucidate the alarmin responses to long-term exercise training, as well as to different duration, types and intensities of exercise. As well, future studies will need to demonstrate downstream signaling pathways in relevant tissues (e.g. skeletal muscle) or immune cells to delineate how exercise stress modulates alarmin and inflammatory signaling [13].

\section{Acknowledgments}

The authors would like to express their gratitude to Mr. Gabriel Lim, Mr. Muhammad Raqib Ashraf, Ms. Wai Yee Woo and Dr. Nao Ohiwa for assistance in data collection and generation, and to Mr. Keefe Chee from BD BioSciences and Dr. Thuan Bui from i-DNA Biotechnology Pte Ltd. for technical assistance. The authors are immensely grateful to Dr. Joost Oppenheim, Dr. Monika Fleshner, Dr. Yifan Yang and Dr. Pavandip Wasan for insightful comments during the preparation of the manuscript. Finally, the authors thank all subjects for their enthusiastic commitment and participation in the study. All authors have read the journal's policy on declaration of conflict of interest and declare no conflict of interest arising from this study.

\section{Authors' contributions}

J.G conceptualized and designed the study. J.G., N.H.A, L.S.H.G and P.L.T conducted the trials. J.G., N.H.A. L.S.H.G and P.L.T performed the experiments. J. G, N.H.A., P. H, L.S.H.G, F.T., A. M, G. T and S.C.W analyzed and interpreted the data. J.G. and L.S.H.G drafted and revised the manuscript. All authors reviewed, commented and approved the submitted manuscript.

\section{Funding}

The project was funded by seed grants (grant number: 20140041) from DSO National Laboratories. The funding body had no role in the study design, data collection or analyses. There are no other sources of funding to declare.

\section{Availability of data and materials}

The datasets used and/or analyzed in this study are available upon request from the corresponding author.

\section{Ethics approval and consent to participate}

All subjects gave written informed consent and underwent comprehensive medical screening. Medically cleared subjects were then enrolled in the study. Baseline testing and all exercise sessions were performed in the Human Performance Laboratory at the Singapore Sports Institute. This study was approved by both Institutional Review Boards of DSO National Laboratories/ Singapore Armed Forces (ethics no. 0023/2014) and the Singapore Sports Institute (ethics no. $\mathrm{PH} / \mathrm{EXP} / 008$ ). All procedures performed on our subjects were in accordance with the ethical standards of the institution and with the 1964 Helsinki declaration and its later amendments.

\section{Consent for publication}

All authors have reviewed the manuscript and give consent for its publication.

\section{Competing interests}

The authors declare that they have no competing interests.

\section{Author details}

1Defence Medical \& Environmental Research Institute (DMERI), DSO National Laboratories, Singapore, Singapore. ${ }^{2}$ Present Address: Centre for Healthy Longevity, National University Health System (NUHS) and Department of Physiology, Yong Loo Lin School of Medicine, National University of Singapore, Singapore, Singapore. ${ }^{3}$ Institute of Sports Science, Exercise Physiology, Training \& Training Therapy Research Group, University of Graz, Gratz, Austria. ${ }^{4}$ School of Chemical and Life Sciences, Singapore Polytechnic, Singapore, Singapore. ${ }^{5}$ Present Address: Nanyang Technological University, Singapore, Singapore. ${ }^{6}$ Singapore Immunology Network (SIgN), Agency for Science, Technology and Research (A-STAR), Singapore, Singapore.

${ }^{7}$ Singapore Sports Institute, Singapore, Singapore.
Received: 11 February 2020 Accepted: 4 March 2020

Published online: 21 March 2020

\section{References}

1. Fehrenbach E, Schneider ME. Trauma-induced systemic inflammatory response versus exercise-induced immunomodulatory effects. Sports Med. 2006;36(5):373-84.

2. $\quad$ Matzinger P. An innate sense of danger. Semin Immunol. 1998;10(5):399-415.

3. Oppenheim JJ, Yang D. Alarmins: chemotactic activators of immune responses. Curr Opin Immunol. 2005;17(4):359-65.

4. Oppenheim JJ, Tewary P, de la Rosa G, Yang D. Alarmins initiate host defense. Adv Exp Med Biol. 2007;601:185-94.

5. Chen GY, Nunez G. Sterile inflammation: sensing and reacting to damage. Nat Rev Immunol. 2010;10(12):826-37.

6. Yang D, Han Z, Oppenheim JJ. Alarmins and immunity. Immunol Rev. 2017; 280(1):41-56.

7. Cohen MJ, Brohi K, Calfee CS, Rahn P, Chesebro BB, Christiaans SC, et al. Early release of high mobility group box nuclear protein 1 after severe trauma in humans: role of injury severity and tissue hypoperfusion. Crit Care. 2009:13(6):R174.

8. Dehbi M, Uzzaman T, Baturcam E, Eldali A, Ventura W, Bouchama A. Toll-like receptor 4 and high-mobility group box 1 are critical mediators of tissue injury and survival in a mouse model for heatstroke. PLoS One. 2012;7(9):e44100.

9. Tong HS, Tang YQ, Chen Y, Qiu JM, Wen Q, Su L. Early elevated HMGB1 level predicting the outcome in exertional heatstroke. J Trauma. 2011;71(4): 808-14.

10. Cotoi OS, Duner P, Ko N, Hedblad B, Nilsson J, Bjorkbacka H, et al. Plasma S100A8/A9 correlates with blood neutrophil counts, traditional risk factors, and cardiovascular disease in middle-aged healthy individuals. Arterioscler Thromb Vasc Biol. 2014;34(1):202-10.

11. He Y, Zha J, Wang Y, Liu W, Yang X, Yu P. Tissue damage-associated "danger signals" influence T-cell responses that promote the progression of preneoplasia to cancer. Cancer Res. 2013;73(2):629-39.

12. Bekos C, Zimmermann M, Unger $L$, Janik $S$, Hacker $P$, Mitterbauer $A$, et al. Non-professional marathon running: RAGE axis and ST2 family changes in relation to open-window effect, inflammation and renal function. Sci Rep. 2016;6:32315.

13. Goh J, Behringer M. Exercise alarms the immune system: a HMGB1 perspective. Cytokine. 2018;110:222-5.

14. Beiter T, Fragasso A, Hudemann J, Niess AM, Simon P. Short-term treadmill running as a model for studying cell-free DNA kinetics in vivo. Clin Chem. 2011:57(4):633-6.

15. Boos CJ, Lamb CM, Midwinter M, Mellor A, Woods DR, Howley M, et al. The effects of acute hypoxia on tissue oxygenation and circulating alarmins in healthy adults. Physiol Res. 2018;67(6):935-43.

16. Walsh RC, Koukoulas I, Garnham A, Moseley PL, Hargreaves M, Febbraio MA Exercise increases serum Hsp72 in humans. Cell Stress Chaperones. 2001; 6(4):386-93.

17. Febbraio MA, Ott P, Nielsen HB, Steensberg A, Keller C, Krustrup P, et al. Exercise induces hepatosplanchnic release of heat shock protein 72 in humans. J Physiol. 2002;544(Pt 3):957-62.

18. Fico BG, Whitehurst M, Slusher AL, Mock JT, Maharaj A, Dodge KM, et al. The comparison of acute high-intensity interval exercise vs. continuous moderate-intensity exercise on plasma calprotectin and associated inflammatory mediators. Physiol Behav. 2018:183:27-32.

19. Mortensen $\mathrm{OH}$, Andersen $\mathrm{K}$, Fischer C, Nielsen AR, Nielsen S, Akerstrom T, et al. Calprotectin is released from human skeletal muscle tissue during exercise. J Physiol. 2008;586(14):3551-62.

20. Maharaj A, Slusher AL, Zourdos MC, Whitehurst M, Fico BG, Huang CJ. Association of calprotectin with leukocyte chemotactic and inflammatory mediators following acute aerobic exercise. Appl Physiol Nutr Metab. 2016:41(1):83-7.

21. Kanda K, Sugama K, Hayashida H, Sakuma J, Kawakami Y, Miura S, et al. Eccentric exercise-induced delayed-onset muscle soreness and changes in markers of muscle damage and inflammation. Exerc Immunol Rev. 2013;19:72-85.

22. Hubal MJ, Chen TC, Thompson PD, Clarkson PM. Inflammatory gene changes associated with the repeated-bout effect. Am J Physiol Regul Integr Comp Physiol. 2008;294(5):R1628-37.

23. Campana L, Santarella F, Esposito A, Maugeri N, Rigamonti E, Monno A, et al. Leukocyte HMGB1 is required for vessel remodeling in regenerating muscles. J Immunol. 2014;192(11):5257-64. 
24. Soehnlein O, Lindbom L. Phagocyte partnership during the onset and resolution of inflammation. Nat Rev Immunol. 2010;10(6):427-39.

25. Walsh NP, Gleeson M, Shephard RJ, Gleeson M, Woods JA, Bishop NC, et al. Position statement. Part one: immune function and exercise. Exerc Immunol Rev. 2011;17:6-63.

26. Yang $\mathrm{D}$, Chen $\mathrm{Q}$, Yang $\mathrm{H}$, Tracey KJ, Bustin M, Oppenheim JJ. High mobility group box-1 protein induces the migration and activation of human dendritic cells and acts as an alarmin. J Leukoc Biol. 2007;81(1):59-66.

27. Rouhiainen A, Kuja-Panula J, Wilkman E, Pakkanen J, Stenfors J, Tuominen RK, et al. Regulation of monocyte migration by amphoterin (HMGB1). Blood. 2004;104(4):1174-82

28. DeMarco RA, Fink MP, Lotze MT. Monocytes promote natural killer cell interferon gamma production in response to the endogenous danger signal HMGB1. Mol Immunol. 2005;42(4):433-44.

29. Matzinger P. Tolerance, danger, and the extended family. Annu Rev Immunol. 1994;12:991-1045.

30. Craig CL, Marshall AL, Sjostrom M, Bauman AE, Booth ML, Ainsworth BE, et al. International physical activity questionnaire: 12-country reliability and validity. Med Sci Sports Exerc. 2003;35(8):1381-95.

31. Seiler KS, Kjerland GO. Quantifying training intensity distribution in elite endurance athletes: is there evidence for an "optimal" distribution? Scand J Med Sci Sports. 2006;16(1):49-56.

32. Hristov M, Schmitz S, Nauwelaers F, Weber C. A flow cytometric protocol for enumeration of endothelial progenitor cells and monocyte subsets in human blood. J Immunol Methods. 2012;381(1-2):9-13.

33. Thomas JR, Salazar W, Landers DM. What is missing in p less than .05? Effect size. Res Q Exerc Sport. 1991;62(3):344-8.

34. Tibana RA, de Almeida LM, Frade de Sousa NM, Nascimento Dda C, Neto IV de Almeida JA, et al. Two consecutive days of crossfit training affects Pro and Anti-inflammatory cytokines and osteoprotegerin without impairments in muscle power. Front Physiol. 2016;7:260

35. Clarkson PM, Hubal MJ. Exercise-induced muscle damage in humans. Am J Phys Med Rehabil. 2002;81(11 Suppl):S52-69.

36. Mooren FC, Lechtermann A, Fobker M, Brandt B, Sorg C, Volker K, et al. The response of the novel pro-inflammatory molecules S100A8/A9 to exercise. Int J Sports Med. 2006;27(9):751-8.

37. Fleshner M, Campisi J, Johnson JD. Can exercise stress facilitate innate immunity? A functional role for stress-induced extracellular Hsp72. Exerc Immunol Rev. 2003;9:6-24.

38. Fruhbeis $C$, Helmig S, Tug S, Simon P, Kramer-Albers EM. Physical exercise induces rapid release of small extracellular vesicles into the circulation. J Extracell Vesicles. 2015;4:28239.

39. Leicht CA, Paulson TA, Goosey-Tolfrey VL, Bishop NC. Arm and intensitymatched leg exercise induce similar inflammatory responses. Med Sci Sports Exerc. 2016;48(6):1161-8.

40. Graff RM, Kunz HE, Agha NH, Baker FL, Laughlin M, Bigley AB, et al. beta2adrenergic receptor signaling mediates the preferential mobilization of differentiated subsets of CD8+ T-cells, NK-cells and non-classical monocytes in response to acute exercise in humans. Brain Behav Immun. 2018;74:143-53.

41. Tang D, Kang R, Xiao W, Jiang L, Liu M, Shi Y, et al. Nuclear heat shock protein 72 as a negative regulator of oxidative stress (hydrogen peroxide)induced HMGB1 cytoplasmic translocation and release. J Immunol. 2007; 178(11):7376-84.

42. Tang D, Kang R, Xiao W, Wang H, Calderwood SK, Xiao X. The antiinflammatory effects of heat shock protein 72 involve inhibition of highmobility-group box 1 release and proinflammatory function in macrophages. J Immunol. 2007:179(2):1236-44.

43. van Eden W, Spiering R, Broere F, van der Zee R. A case of mistaken identity: HSPs are no DAMPs but DAMPERs. Cell Stress Chaperones. 2012;17(3):281-92.

\section{Publisher's Note}

Springer Nature remains neutral with regard to jurisdictional claims in published maps and institutional affiliations.

Ready to submit your research? Choose BMC and benefit from:

- fast, convenient online submission

- thorough peer review by experienced researchers in your field

- rapid publication on acceptance

- support for research data, including large and complex data types

- gold Open Access which fosters wider collaboration and increased citations

- maximum visibility for your research: over $100 \mathrm{M}$ website views per year

At BMC, research is always in progress.

Learn more biomedcentral.com/submissions 